\title{
Los entramados de lo público: república, plebe, publicidad y población
}

\author{
The Conceptual Universe of the Public: \\ Republic, Plebs, Publicity and Population
}

Francisco A. Ortega

Universidad Nacional de Colombia

fortega@unal.edu.co

\begin{abstract}
$\overline{\text { RESUMEN }}$
En este ensayo propongo abordar de manera integral las múltiples experiencias de lo público que se manifiestan, en buena parte de nuestras sociedades contemporáneas, aisladas y fracturadas, como si no tuvieran relación una con otra. La premisa es, por el contrario, que aquello que se expresa inicialmente como mero adjetivo — públicas_adquiere la posibilidad de ser comprendido de manera novedosa cuando encuentra su núcleo de sentido común articulado por el sustantivo -lo público-. Aún más, esa nucleación de sentidos en torno al sustantivo permite responder críticamente a una sociedad —como la colombiana_históricamente polarizada por grandes inequidades y fuertes violencias sociales, con acelerados procesos de burocratización y altos niveles de corrupción e ineficiencia, y que está íntimamente conectada a una economía global.
\end{abstract}

Palabras claves: público, república, pueblo, plebe, opinión pública, población.

\section{ABSTRACT}

In this essay, I address the multiple experiences of the public (such as public policy, public health, public opinion or the publics), many of which we experience in a fragmented manner, as if these experiences of the public had no relation to each other. However, my premise is that what initially appears as a non-cohering adjective - the public in, for instance, public policy - might be understood in a comprehensive and innovative way when we unearth its shared semantics articulated by the substantive -the public. Furthermore, such nucleation of meanings around the noun allows us to conceive critical and innovative forms of response to a society historically polarized by social inequalities and violence, with elevated processes of bureaucratization and high levels of corruption and inefficiency, which is intimately connected to the global economy.

Keywords: public, republic, people, plebs, public opinion, population. 


\section{Del artículo neutro}

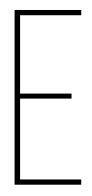

l supuesto que anima buena parte de esta reflexión está recogido en el artículo neutro que acompaña el sustantivo que nos interesa, es decir, lo público ${ }^{1}$. Gramaticalmente, este deíctico indeterminado y neutro acompaña conceptos abstractos, no sustantivos concretos. En tanto abstracción, el artículo neutro recoge e incluye las concreciones particulares expresadas por los artículos definidos, es decir, aquellos que determinan frases como: las políticas públicas, la educación o la salud pública, el transporte público, el espacio o la vida pública, el público, etc. En los ejemplos anteriores, se hace evidente que el artículo definido relega lo público a la condición de adjetivo. Por lo tanto, bien podría decirse que este escrito está orientado a esclarecer la especificidad de ese pequeño artículo lo, mucho más idiosincrático de lo que puede parecer en primera instancia. Es mi convicción que ese ejercicio de abstracción traslada lo que aparece heterogéneo - como las manifestaciones de lo público ya mencionadas- a un escenario que nos permite visibilizar tensiones compartidas, continuidades históricas y lógicas comunes que atraviesan estos campos aparentemente tan disímiles.

El ejercicio de abstracción no constituye un gesto inédito. Ya el filósofo político Claude Lefort $(1991,19-20)$ había hecho una distinción parecida entre la política y lo político. Su discípulo Pierre Rosanvallon retomó esa distinción en la lección inaugural en el Colegio de Francia, en el 2002. En ese texto define la política como el saber que "se ocupa del funcionamiento de los partidos y las instituciones, escruta los procesos y mecanismos de toma de decisiones e interpreta el resultado de sondeos, referendos, consultas y elecciones" (Rosanvallon 2003, 15). El objetivo principal del análisis de la política — continúa Rosanvallon- es entender las razones por las cuales los diversos actores de esta - los políticos, los grupos de presión, los funcionarios, etc.- actuaron de una u otra manera, e identificar los cálculos subyacentes en sus transacciones.

Lo político, en cambio, corresponde a "la formación y evolución de los sistemas de representación que gobiernan el modo como una época, un país o

1 Agradezco a los integrantes del grupo Usos y Sentidos Contemporáneos de lo Público por el maravilloso ejercicio de reflexión conjunta que hemos realizado a lo largo de dos años. A Margarita Chaves, gracias por impulsarme a publicar este planteamiento inicial; a Liliana Chaparro y a los evaluadores anónimos, gracias por sus lecturas críticas, estimulantes y brillantes a la vez. Debido a consideraciones del comité editorial de la revista, esta versión del ensayo privilegia el nivel lógico argumental; una versión más robusta en sus consideraciones históricas aparecerá próximamente. 
unos grupos sociales conducen su acción e imaginan su porvenir” (Rosanvallon 2003, 128-129). Por eso mismo, lo político nos remite a un campo, en tanto que este último es un "lugar donde se entrelazan los múltiples hilos de la vida de hombres y mujeres, aquello que brinda un marco tanto a sus discursos como a sus acciones” (Rosanvallon 2003, 16). Pero, asimismo, lo político nos remite, según Rosanvallon, a un trabajo, en tanto que es igualmente el proceso por el cual un agrupamiento humano negocia, siempre conflictivamente, los rasgos de una comunidad, y así establece las reglas implícitas y explícitas que lo norman. A través de estas dos dimensiones, lo político aborda de manera integral los escenarios y la evolución de las racionalidades políticas constitutivas de una comunidad.

En este ensayo - y en el programa de investigación que él anuncia- apelo al artículo neutro para abordar de manera integral las experiencias de lo público, que se manifiestan en buena parte de nuestras sociedades contemporáneas de manera aislada y fracturada, como si no tuvieran relación una con otra, como si lo que fuera público en la educación o la salud no tuviera mucho que ver con todas aquellas otras esferas de la experiencia social que aparecen adjetivadas de tal manera. La premisa es, por el contrario, que aquello que se manifiesta inicialmente como mero adjetivo — públicas - adquiere la posibilidad de ser comprendido de manera integral y novedosa cuando encuentra su núcleo de sentido común articulado por el sustantivo - lo público-. Aún más, esa nucleación de sentidos en torno al sustantivo permite responder de manera crítica a una sociedad - como la colombiana - históricamente polarizada por grandes inequidades y fuertes violencias sociales, con acelerados procesos de burocratización y altos niveles de corrupción e ineficiencia, y que está íntimamente conectada a una economía global. Reunidas todas estas experiencias bajo el artículo neutro, resulta posible investigar el orden simbólico de lo general o común; aparece como viable considerar aquellos escenarios en los que se instituye lo que nos constituye como común en tanto comunidad y los procesos o trabajos por medio de los cuales le damos rasgos propios a esa "comunalidad". Aparece entonces lo público como el centro nervioso del cual procede nuestra institución.

Ese ejercicio de abstracción —que apunta a la dimensión estructurante de lo público - nos remite entonces a un entramado conceptual que toca diversos aspectos fundamentales de la experiencia sociopolítica contemporánea. Tal vez se hace necesario aclarar en este momento que cuando hablamos de la dimensión conceptual no nos referimos a abstracciones, a lo que sería el puro y lúcido -aunque irreal - universo de las ideas. Al contrario, los entramados conceptuales son estructuras semántico-sociales con pretensiones de generalidad que recogen y plasman la multiplicidad de la experiencia vivida y, a la vez, constituyen 
horizontes de expectativas a través de los cuales motivamos nuestras acciones políticas ${ }^{2}$. Lo público, en tanto entramado conceptual, puede ser pensado como una estructura de pasado-futuro, es decir, como un conjunto de experiencias sociales acumuladas desplegadas sobre un horizonte de expectativas plausibles.

A ese entramado conceptual no le corresponde un significado único y correcto, sino que tiene la capacidad de "incorpora[r] una pluralidad de significados en pugna, y engloba[r] en ese solo significante un rico contexto histórico, social y político" (Koselleck 1993, 117). Hace falta insistir en esto para comprender lo que sigue: desde esta perspectiva, un concepto sociopolítico fundamental se diferencia de otras palabras - que no son conceptos- en que su polisemia hace imposible la definición precisa. Y, en efecto, lo público, en tanto entramado conceptual, no tiene una definición técnica, correcta o definitiva; designa, en cambio, un campo de definiciones encontradas ${ }^{3}$. Sin duda, a veces - sobre todo en tiempos de relativa estabilidad sociopolítica-, puede parecer que un concepto adquiere un sentido invariable y definitivo, pero su carácter polémico e inestable está siempre presente y se vuelve evidente durante periodos de transición, crisis o convulsión sociopolítica.

Por concepto, entonces, entiendo una estructura histórica que designa un campo de enfrentamientos y relaciones de poder en los que ciertas formas de comprender se han impuesto sobre otras. En esa medida, importa hablar tanto de los nuevos sentidos de lo público como de los antiguos, en el entendido de que lo nuevo siempre se elabora a partir de lo existente, incluso de lo antiguo que ya no es vigente. Sin fluir subordinadamente desde lo antiguo, lo nuevo solo se entiende a partir de las múltiples posibilidades que lo constituyen como pasado. Por eso, acercarse a lo público como un entramado conceptual supone $-\mathrm{y}$ este es el argumento principal de este ensayo- que su comprensión, así como su intervención, requieren de un trabajo histórico. Solo de esa manera se hace visible el conjunto de experiencias compartidas que han hecho posible lo público en nuestro país y que constituyen el patrimonio fundacional sobre el cual se construye nuestra historia. desarrollada por Reinhart Koselleck, Futuro pasado. Para una semántica de los tiempos históricos (1993). de Koselleck, el concepto no es una unidad semántica que define el significante en cuestión sino un conjunto de versiones que confluyen de manera polémica en la palabra. Esa confluencia hace de los conceptos entramados. 


\section{Lo público: un problema urgente}

El artículo neutro podría suponer una experiencia neutra. Lejos de ello, lo público aparece hoy en día como un problema ineludible que requiere soluciones urgentes. Una de las narrativas vigentes de ese problema señala la erosión progresiva y relativamente sistemática de lo público por parte de la consolidación y expansión de los intereses privados y transnacionales, que ven en su existencia un obstáculo para la realización de sus objetivos. El diagnóstico es contundente: el desgaste de lo público en el marco de las políticas neoliberales imperantes desde el consenso de Washington (1989) atenta contra la soberanía, va en franco detrimento de las formas de organización colectiva y comunitaria, y genera a su vez una tendencia perniciosa para la viabilidad de la comunidad ${ }^{4}$.

Esta formulación del problema depende de tres certezas. En primer lugar, que lo público completa y complementa la noción de justicia, ya que es requisito para la consecución del bien común, el buen gobierno y la defensa de los intereses solidarios. Lo público aparece, entonces, vinculado a un estado que garantiza el ejercicio de los derechos liberales y, además, a un orden redistributivo —material, de acceso institucional y simbólico— que nivela aquellas desigualdades que instauran condiciones de dependencia y dominio. En segundo lugar, lo público elabora una noción de ciudadanía en tanto que concilia la diversidad de intereses particulares y la voluntad general, la tensión entre las aspiraciones legítimas de los individuos y las condiciones apropiadas para la práctica de una ciudadanía equitativa. En tercer lugar, lo público está vinculado a una noción de soberanía en la medida en la que esta expresa la capacidad fundamental de toda comunidad política para garantizar su integridad ante las amenazas internas, aquellas que usurpan el poder del pueblo, o externas, aquellas que vulneran su propia viabilidad como comunidad en el llamado concierto de naciones. En este contexto, lo público es la infraestructura que permite propender al principio de autarcía o de autosuficiencia, fundamental para el concepto de nación, nuestro equivalente del antiguo y prestigioso término escolástico de comunidad perfecta.

El economista británico John Williamson acuña, en 1989, el término el consenso de Washington para designar el conjunto de diez preceptos de política económica que todo gobierno debería adoptar para lograr un óptimo desarrollo económico. De acuerdo con Williamson, estos diez preceptos eran compartidos por muchos de los nuevos mandatarios latinoamericanos del periodo y por varias de las instituciones más influyentes de promoción y asesoramiento económico (Fondo Monetario Internacional [FMI], Banco Mundial, etc.) que operaban desde Washington (Williamson 1990, 7-38). Para una visión de conjunto que explica el ascenso del consenso entre intelectuales y burócratas a nivel global, véase Stanislaw y Yergin (1998). Para una visión crítica del proceso, véase Harvey (2005). 
A la luz de estas certezas, lo público adquiere substancia no solo en oposición a lo privado, sino fundamentalmente en relación con los intereses particulares depredadores, es decir, con las tendencias egoístas - en este caso encarnadas en el capital transnacional - que destruyen la posibilidad de la vida en común. Lo público aparece vinculado a un estado máximo, fuerte, protector e interventor, que se asume como algo naturalmente digno de ser defendido: el patrimonio de la comunidad ante los diversos egoísmos de la no-ciudadanía, la salvaguarda de su integridad en la cada vez más incierta globalización, el nombre sobre el cual se asienta su bienestar y dignidad. Lo público se presenta entonces como un bien civilizatorio o una conquista moral, o como un eslabón en el desarrollo social del ser humano.

Sin embargo, se hace necesario reconocer que esta versión no constituye la única narrativa existente sobre lo público. Señalemos que, de hecho, existe una visión diametralmente opuesta que disfruta de cierto aprecio entre importantes sectores sociales del país, aun cuando ellos no necesariamente se vean reflejados en los lectores de este artículo. No dejemos por eso de caracterizarla. Para esa visión, el problema corresponde a los excesos en que incurre una expansión de lo público, una invasión agresiva de los órdenes privados y domésticos por parte de los poderes públicos que vulnera la privacidad y la dignidad, y amenaza las libertades individuales ${ }^{5}$. Como la anterior, esta visión también está vinculada a nociones de justicia y ciudadanía — aunque su valoración sea opuesta-, mientras que la idea de soberanía prácticamente desaparece a favor de un cosmopolitismo integrador.

En primera instancia, esta versión de lo público está unida a una noción de injusticia. La injusticia, en tanto expansión de lo público, constituye una obstrucción al ejercicio de las libertades fundamentales. En esa versión, los intereses particulares no tienden a vulnerar la concurrencia al bien común sino que -en la disparidad de sus aspiraciones- la constituyen. Lo público es un lugar de mínimos que buscan garantizar la libre competencia de individuos, también libres, en el mercado y otros ámbitos sociales. La función del estado, por lo tanto, no es la de imponer unos valores colectivos - lo público-, puesto que estos no preexisten a la participación interesada de los agentes sociales, sino permitir -e incluso estimular - que estos agentes elaboren esos valores a través de su libre accionar. El estado que excede este mandato minimalista entorpece el ejercicio

$5 \quad$ Esta visión sustenta el ya mencionado consenso de Washington. Si bien tiene fundamentos teóricos que se remontan al llamado liberalismo clásico, la tradición libertaria y los trabajos económicos y filosóficos de Friedrich Hayek y Milton Friedman resultan fundamentales. Véase, por ejemplo, el clásico texto de Hayek, The Road to Serfdom (1944) o el polémico Capitalism and Freedom (1962), de Friedman. 
de las libertades individuales y adquiere un carácter despótico. La injusticia también, en tanto constituye lo público — contrario a lo particular-, no tiene un valedor propio que la salvaguarde de la degradación y la corrupción. De ese modo, lo público promueve la ineficiencia, es decir, inhibe el adecuado desempeño de los poderes públicos y se constituye en campo privilegiado para la fuga de recursos comunes.

Por todo eso, la expansión de lo público es un principio de entropía social en tanto que aniquila el único soporte de la felicidad social - la libertad y el interés propio- e impone una falsa igualdad que desconoce la diversidad y la complejidad humana. Está además vinculada al deterioro de la ciudadanía, pues lo público tiende a gestar una cultura paternalista del subsidio y el privilegio que desestimula la industria y la iniciativa privada, e inhibe el impulso emancipatorio que le ha dado fuerza a la figura del ciudadano. Por último, esta visión minimalista renuncia a la idea de lo público como ejercicio de la soberanía nacional frente a la fuerza integradora del capital transnacional. La idea que sustenta esta visión no es ya la de la autarcía local, la cual, según anotan quienes la han propuesto, no solo resulta obsoleta sino que constituye el verdadero impedimento para la interdependencia global, la única forma de lograr un grado de viabilidad comunal ante los procesos inevitables de globalización.

Tenemos entonces, por lo menos, dos versiones del problema de lo público: una expansiva, que advierte sobre la degradación de lo público, y una minimalista, que previene sobre los riesgos de lo público degradado. Estas dos versiones, con todos sus matices intermedios, se disputan el sentido de lo público y constituyen su campo de acción política. Notemos tres rasgos que conjuntan estas argumentaciones opuestas. En primer lugar, las diferentes posiciones están estructuradas a partir de un repertorio temático compartido. Es decir, el desacuerdo no resulta de la heterogeneidad de conceptos y argumentos en cada una de las posiciones, sino de valoraciones contrarias de los mismos conceptos (i. e., justicia, soberanía, ciudadanía, y podemos agregar república, pueblo, etc.). Esto significa que la distancia que media el desacuerdo entre una posición y otra constituye el espacio de la disputa política contemporánea. Es decir, el desacuerdo conceptual nos permite entender el problema político de lo público como la lucha por parte de grupos sociales con argumentos contrarios por consolidar e imponer una definición de lo público sobre otras posibles. Pero esa oposición no es externa e independiente del sentido de lo público. Lo público no tiene un sentido previo a esa argumentación.

En segundo lugar, la disputa está caracterizada por un enfrentamiento entre dos culturas políticas consolidadas en torno a cada una de las posiciones 
contrarias. Este enfrentamiento adquiere un alto grado de polarización, lo que dificulta o inhibe cualquier forma de persuasión posible; lo que existe es un abismo entre las dos posiciones argumentales. De ese modo, la disputa política aparece como un encuentro formidable entre dos valoraciones opuestas en torno a la finalidad de la vida social. El hecho de que se manifieste como convicción y enfrentamiento, y no como campo posible de deliberación y persuasión, evidencia una fatiga de sus posibilidades políticas. Lo público es, por lo tanto, un concepto en crisis, paradójicamente exiguo en su potencial para reinventarse. Si se ha de concebir la discusión de lo público más allá de un enfrentamiento infructuoso, es necesario intervenir ese abismo y zarandear sus certezas. Hoy, más que nunca, es necesario incitar la imaginación política.

Finalmente, ambos argumentos comparten la tendencia a ver el problema como una situación relativamente reciente - una suerte de perversión de un ideal de lo público previamente realizado o, por lo menos, que había sido claramente enunciado-, pervertido ya bien por la penetración agresiva del neoliberalismo, o por los excesos propios del populismo y el estatismo hispanoamericano ${ }^{6}$. Es decir, ambas posiciones desconocen el sustrato común de experiencias sociales que las han hecho posibles a lo largo de doscientos años, desconocen la historia contenciosa - pero también mutuamente constitutiva - que precede en mucho al encuentro de fuerzas actual. Esto es importante entenderlo en su formulación más radical. Lo público no solo tiene historia; lo público fundamentalmente es historia ${ }^{7}$. Por eso, la oposición no es entre dos posiciones externas a lo público - es decir, dos valoraciones que existen frente a algo previamente constituidosino que es interna para cada uno de los campos.

Tener una visión ahistórica es aceptar los términos del debate tal y como han sido definidos por los actores más eficaces; significa asumir acríticamente unos puntos de partida - unos supuestos valorativos y argumentativos-como si fueran naturales cuando, en realidad, han sido contenciosos a lo largo de la historia y su eficacia contemporánea es un efecto de poder. Ese ahistoricismo permite, a su vez, suponer que el concepto de lo público es evidente, estable y definible, desde los presupuestos autónomos de cada uno de los campos en disputa, y que no es susceptible de ser redefinido.

Para ambas narrativas, lo público emerge a finales del siglo XVIII y principios del XIX, y se consolida durante la transición del antiguo régimen a lo que podríamos llamar, de manera tentativa, una modernidad política del estado. ria. Hay que considerar más radicalmente que la democracia es una historia [...]" (25). 
Por su parte, una mirada conceptual nos indica que lo público no es evidente, que no es estable, que su sentido es siempre relacional y que en cualquier momento es susceptible de ser intervenido. Una mirada histórica - lo que llamo una arqueología conceptual de lo público- no solo hace evidente ese carácter fluido y contencioso de lo público, sino que además es un ingrediente necesario para volver a pensarlo políticamente. No se trata por lo tanto de ofrecer una historia de las instituciones o de las ideas de lo público. Más bien, interesa explorar la constelación conceptual que hizo posible el complejo experiencial que reconocemos como lo público y reconocer que esa historia nos descubre un escenario en el que se argumenta mucho más de lo que parece evidente. Es la condición para reimaginar las posibilidades políticas propias de lo público.

\section{Cuatro nodos de sentido}

Buena parte de la literatura contemporánea asimila lo público al estado, y en particular a la esfera en la que se llevan a cabo las relaciones entre este y los ciudadanos, mientras que lo privado usualmente remite al ámbito en el cual se relacionan los particulares entre sí. Sin embargo, una mirada de larga duración nos indica que el estado y lo privado son apenas dos tributarios entre muchos más de los que enriquecen el caudal conceptual de lo público; son apenas dos facetas de un entramado conceptual mucho más complejo. Quienes parten de esa oposición contemporánea contemplan lo público como un producto acabado de una teleología secular liberal en la que el estado encarna el fin de la historia.

Sin embargo, desde lo conceptual, lo público es una franja de experiencia y un horizonte de expectativas en constante disputa desde el siglo XVIII, que tiene que ver con tres nodos de significado de la experiencia social. Estos tres nodos conceptuales recogen y elaboran los tres temas que registramos en las argumentaciones sobre lo público - la justicia, la ciudadanía y la soberanía-, pero desde estructuras semántico-políticas de larga duración que tienen como punto de arranque decisivo finales del siglo XVIII y que encontraron, a principios del siglo XIX, un momento fuerte de inflexión, en realidad, diríamos, de refundación. En primer lugar, la república, entendida como la comunidad política que hace posible y se sustenta en las relaciones de igualdad, libertad y bien común. En segundo lugar, el pueblo, entendido simultáneamente como el agente político de la transformación y el sujeto de la soberanía. En tercer lugar, la publicidad, entendida como la articulación social de la voluntad general y el instrumento de la ilustración e 
instrucción del pueblo. Estos tres nodos conceptuales están atravesados por un eje de sentido que funciona como dispositivo de control: la población, entendida simultáneamente como la mayor riqueza de la comunidad —los habitantes, el trabajo y la productividad-y de valoración, vigilancia y autovigilancia de los habitantes de la república. La población aparece como la exaltación de los miembros de la comunidad dentro de una concepción de la economía política.

Esta cadena conceptual hace posible la emergencia de lo público en el sentido contemporáneo. Nos presenta lo público simultáneamente como un escenario, un sujeto y un trabajo, una estructura que con frecuencia es movilizada para profundizar la experiencia democrática y con igual frecuencia se presta para imponer una lógica administrativa y disciplinar. Como debe resultar claro, las constelaciones conceptuales que configuran el sentido de lo público en un momento dado de la historia varían como resultado de diversos factores sociales, económicos y políticos. A modo de hipótesis, permítaseme proponer que la historia de lo público en Colombia tiene cuatro momentos significativos de elaboración conceptual. La combinatoria de los nodos conceptuales cambia en cada uno de esos momentos.

Durante el periodo que va de 1770 hasta aproximadamente 1870, se gestan lentamente los elementos propios de lo público iberoamericano. En la primera mitad del periodo, el nodo en torno a la publicidad y al dispositivo población aparece por primera vez como protagonista decisivo de la vida social y política. Por su parte, los nodos república y pueblo experimentan una transformación radical durante la segunda mitad del periodo que los convierte en piezas fundamentales de la nueva institucionalidad. Este proceso se consolida y acelera a partir de la institución de la república democrática representativa, en 1821. Durante el periodo en cuestión, aparecen las tensiones fundacionales de lo público.

En el periodo que va de 1870 hasta aproximadamente 1930, la república y el pueblo se consolidan de manera definitiva, tanto en el imaginario como en la práctica comunal. Sin embargo, tanto una como el otro se despolitizan y adquieren un carácter pasivo e incluso social-administrativo. Es precisamente en ese momento que el pueblo americano surge como el sujeto nacional en potencia, un sujeto biorracializado, simultáneamente problema y promesa. Según los comentaristas del periodo, el conjunto socialmente heterogéneo llamado pueblo es inmoral y proclive a la violencia, y debe ser sometido a la civilización. Aparece la llamada cuestión social, el primer gran conjunto de políticas públicas que hizo del pueblo su objeto de atención sistemática. La república, por su parte, se convierte en el escenario privilegiado de ese disciplinamiento social y moral.

Durante el periodo que va de 1930 hasta aproximadamente 1980, emerge lo popular nacional como la forma particular de construir lo público. Con el 
proceso de urbanización y el acelerado ingreso de amplios sectores al proletariado industrial, el problema de la representación adquiere un papel protagónico en la vida política. El populismo y el nacionalismo emergen como respuesta a la crisis de los partidos oligárquicos y al ordenamiento global de las posguerras.

Finalmente, desde 1980 hasta el presente, se vive una crisis prolongada de lo público como concepto fundamental de lo político. Lo público se debate entre ser reemplazado, por una modalidad técnico-administrativa de la vida social y retomar la defensa robusta de la justicia, la ciudadanía y la soberanía como ejes centrales de la vida política, que garantizan el ideal emancipatorio de la vida en común. Si los esfuerzos por transformar las esferas de lo público en administración social tienen éxito, la experiencia, el prospecto y la potencia de lo político resultarán visiblemente disminuidos. Es por eso, insisto, que la cuestión de lo público atraviesa y llena de contenido la naturaleza de lo político en el presente. Se constituye en la tensión fundamental que mantiene viva la dimensión política del presente.

Cabe decir que resulta improcedente, además de imposible, ofrecer una historia del concepto en el espacio que me queda. Por eso, por la naturaleza misma de este artículo y por el estado de mi investigación, solo me detendré en los dos primeros momentos, que comprenden el largo siglo XIX. Esto responde a un intento por, en primer lugar, esbozar el sedimento conceptual sobre el cual se elabora esta larga historia de lo público; en segundo lugar, enrarecer o desnaturalizar los términos bajo los cuales lo público aparece como un problema en el presente y del presente; y, finalmente, evidenciar sentidos y posibilidades que permanecen, por el momento, opacos pero latentes, susceptibles de ser intervenidos, revitalizados o movilizados en aras de una acción política.

\section{La república virtuosa y la república aérea}

Durante las dos últimas décadas del siglo XVIII, la Nueva Granada asiste a una profunda transformación social, económica y cultural que resulta inseparable de lo que ocurre en otros territorios bajo el gobierno de la monarquía hispánica. El léxico político cultural sufre variaciones significativas. República es uno de esos términos claves y esas transformaciones lo convertirán en uno de los conceptos fundamentales de la historia que comienza con una ruptura con las formas monárquicas y con la constitución de una comunidad independiente por fuera de la comunidad hispánica. 
Hasta finales del siglo XVIII, el vocablo república tenía un amplio repertorio de significados, aunque en ningún caso acarreaban un sentido político fuerte. Sin duda, la república designaba la comunidad política susceptible de volverse perfecta, pero esta calidad no se obtenía a través de una práctica ciudadana que implicara la igualdad, la libertad o el ejercicio de la soberanía política. La república católica ibérica no se refería a una comunidad política activa, sino pasiva. La obediencia era una de las características fundamentales de la "república feliz". Como señala el capuchino Joaquín de Finestrad, pacificador del Socorro, después del levantamiento comunero de 1781, la “obediencia [absoluta] es el vínculo que une entre sí las partes de la república; este es el espíritu vital en el que participan tantos millones de hombres que por sí mismos solo servían de carga y de despojo si les faltase el alma del imperio” (Finestrad 2000, 310). En la tradición intelectual y política de la monarquía ibérica, la república cristiana designaba una comunidad virtuosa, presidida por un príncipe piadoso y ordenada por los principios de caridad, fidelidad y obediencia, necesarios para la salvación. Los hombres no eran ciudadanos virtuosos por naturaleza sino sujetos de pasiones y estaban inclinados al pecado: no eran un pueblo soberano sino una multitud pecadora. El pueblo no tenía un papel en el gobierno más allá del consentimiento. Se requería, en cambio, un gobierno fuerte que sirviera de dique a los vicios. Solo aquellos pocos vasallos ilustrados que exhibían un "espíritu público”, que así era entendido el patriotismo que elevaba el individuo a la condición de preminencia, podían contribuir a la utilidad de la república ${ }^{8}$.

El panorama va a cambiar de manera dramática a finales del siglo XVIII, cuando diversos grupos sociales se apropian de un lenguaje republicano, que podemos denominar de manera convencional humanismo cívico, y que insistía en el ejercicio de la libertad y la igualdad —concebidos, eso sí, de manera diversa- como los fundamentos para la consecución del bien común y la felicidad general $^{9}$. Estos lenguajes, las herramientas con las cuales se pueden construir diversas posibilidades políticas, penetraron de tal manera la cultura hispánica que, para 1780, el diccionario de la Real Academia de la Lengua señalaba que la república es "el gobierno del público. Oy se dice del gobierno de muchos, como distinto del gobierno Monarchico [sic]” (1780). Para los neogranadinos constructores de las primeras repúblicas, esta última definición - la que designa un sistema de gobierno distinto y opuesto a la monarquía - se constituirá tres décadas

\footnotetext{
8 Véase "Avisos de Hebephilo" (1791, 58).

9 Para una definición y una trayectoria del republicanismo o humanismo cívico, véase Pocock (2002).
} 
después en el referente principal de sus debates políticos. La república era distinta porque dependía de la virtud pública, mientras que la monarquía dependía del poder y la majestad del soberano, y era además opuesta porque exigía el cultivo de la libertad y la igualdad, mientras que la monarquía exigía el cultivo del honor $^{10}$. En principio, pues, la forma republicana demandaba la elaboración de una práctica cívica y una estructura institucional que promovía y sostenía la virtud, y garantizaba el disfrute de la igualdad y la libertad.

La republica americana se desarrolla a lo largo del siglo XIX inserta en una suerte de paradoja. El sistema republicano exige un pueblo virtuoso para su estabilidad y prosperidad; un pueblo industrioso y capaz, a través de su espíritu patriota y del uso de sus facultades deliberativas, de generar riqueza y de llegar a objetivos comunes. Sin embargo, para los mismos republicanos entusiastas del momento, el pueblo americano no era virtuoso; vivía — como señala Bolívarbajo el "triple yugo de la ignorancia, de la tiranía y del vicio”; no poseía, según la prosa de la época, las “nobles pasiones, que son el resorte de las virtudes cívicas” (Bolívar 2009, 75; Laso de la Vega 1826, 13). El diagnóstico era repetido y coincidía en que varios eran los factores que habían contribuido al decidido embrutecimiento del pueblo: el régimen colonial español, que lo envileció al cerrarle las puertas a su industria y acostumbrarlo a sus cadenas; la falta de oportunidades y la inexperiencia en cuestiones políticas; la escasez de la población diseminada sobre un amplio territorio; la proliferación de clases diversas y la heterogeneidad de intereses; y el estado salvaje de varios de sus grupos sociales. "En consecuencia”, señalaba un cercano colaborador de Bolívar, "no se conoce en nuestras jentes el espíritu [público], que es el fomento poderoso del amor patrio y el nombre de [americano] apenas tiene en el vulgo un vago é indiferente significado [sic]” (Laso de la Vega 1826, 14).

Las razones esgrimidas constituían un obstáculo formidable para la adopción de la forma republicana pues, como se repetía, haciendo eco de Montesquieu, las instituciones políticas debían ajustarse al pueblo y no al revés. Obstinados, los patriotas americanos insistieron en el carácter republicano del pueblo americano pero advirtieron que todo sistema de gobierno “debería tener á la vista [este diagnóstico] para formar nuestra constitución, so pena de exponernos, ó a retardar nuestra carrera acia la prosperidad, o á sumirnos en los horrores de una libertad dañosa [sic]” (Laso de la Vega 1826, 7). De otro modo, señalaba Bolívar ya en 1812, continuaremos "imaginando repúblicas aéreas, ... procurando alcanzar la perfección política, presuponiendo la perfectibilidad del linaje humano” (11). 
A despecho de la magnitud de estas objeciones, varios estados nacientes adoptaron el sistema republicano. Sin duda, buena parte de esa decisión se debe - como señaló el mismo Bolívar pocos años después- a que el vulgo no aceptaría ningún otro sistema. La apropiación de un ideario republicano por amplios sectores sociales durante las guerras de la independencia había generalizado ciertas expectativas en torno a la libertad civil y la igualdad social.

Muchos republicanos del momento se enfrentaron con cierto optimismo a la posibilidad de obrar el "mayor de los milagros en el orden moral", es decir, la conversión de vasallos envilecidos en ciudadanos virtuosos (Laso de la Vega 1826, 20). Este sería un proceso lento y arduo, pero una república bien fundada sería el escenario propicio para obrar tamaño portento. Evidentemente, el resultado no serán las repúblicas clásicas; entre estas y el sistema que requieren las nuevas repúblicas americanas, señala el ecuatoriano Vicente Rocafuerte en 1823, "debe haber la misma diferencia que existe entre la... altura del agigantado Chimborazo y la humilde elevación del pigmeo Hymeto, entre el estruendo del océano que forma el río Amazonas y el risueño arroyuelo Cephiso” (11-12). La construcción del público — de lo público— en estas nuevas repúblicas americanas requería de procedimientos e instituciones particulares.

La pertinencia y resonancia de la república a lo largo de todo el siglo XIX se debe a la manera particular en que esta tensión se desarrolla en Hispanoamérica. La república se entenderá, a partir de ese primer momento, como un proyecto vigente -el único posible- $-\mathrm{y}$ una sociedad aún por constituir. Al ser estas unas repúblicas que, como dice el pedagogo Simón Rodríguez, todavía no tienen pueblo, requieren que se lleven a cabo dos tareas. En primer lugar, la tarea que ocupará a buena parte de los actores de nuestra historia será la de encontrar la forma de consubstanciar la república, es decir, de definir las instituciones propias que expresen nuestra singular existencia política (i. e., república popular sin pueblo). Con frecuencia, esta supuesta singularidad planteará la república americana como un caso de excepción en el que tanto las instituciones como la misma noción de democracia serán sometidas a profundos rediseños, generalmente con altos contenidos autoritarios, con el fin de darle expresión al sujeto soberano y, simultáneamente, controlarlo. La frecuente apelación a medidas de excepción y la aparición en todo el continente de regímenes nacional-populistas continúan esta línea de desarrollo en el siglo XX.

La segunda tarea a que se dará lugar será la de formar ese pueblo, bien a través de estrategias pedagógicas populares, como proponía Rodríguez, o moralizantes masivas, como corresponderá a buena parte de la institucionalidad de la segunda mitad del siglo XIX. La república y su sucesora a finales del siglo 
XIX y principios del XX, la nación, adoptarán dos elementos de la antigua tradición ibérica para llevar a cabo esa tarea. En primer lugar, la idea de la virtud cívica cristiana - o la moral, en el lenguaje propio de la segunda mitad del siglo XIX-, que es el elemento central de la constitución de una comunidad política, la fuerza social que se contrapone al egoísmo y a la ignorancia, inhibidores del bien común. En segundo lugar, el carácter moralizador de la autoridad política, la instancia responsable de la conversión de la plebe en ciudadanos.

El aparato administrativo fue diseñado para acometer esa doble tarea, y lo público se concibió como el conjunto de escenarios e instrumentos disponibles para cumplir con la tarea civilizatoria del gobierno. Seis fueron sus frentes en el siglo XIX: la carrera militar, la administración burocrática, la educación, la justicia, la hacienda y el fisco, y el sistema de partidos y de representación. Las élites tendían a favorecer un aparato administrativo enérgico y emprendedor, pero la ausencia de recursos fiscales, de infraestructura, de capacidad técnica y la misma división interna de las élites gobernantes impidieron que el estado construyera un sector público robusto. En consecuencia, la Iglesia - actuando de manera subsidiaria ante el estado- emergió como una institución capaz de suplir buena parte de esas necesidades administrativas.

\section{Pueblo: el monstruo de dos cabezas}

Si república designa el escenario de lo público, el pueblo es su sujeto, quien le da vida y quien se ocupa de él. No es fortuito, por lo tanto, que pueblo sea el otro gran nodo conceptual que sufre transformaciones profundas a finales del siglo XVIII y principios del XIX, y que arroja un horizonte de posibilidades conceptuales y políticas que incide sobre los crecientes sentidos de lo público. Previo a 1808, la noción de pueblo se refería, fundamentalmente, al conjunto de habitantes que eran plebeyos, a diferencia de los patricios del reino ${ }^{11}$. En el contexto neogranadino, el pueblo incluía a los indios, mestizos, mulatos, castas, negros e incluso blancos empobrecidos, es decir, la población heterogénea del virreinato,

11 Existen otros sentidos de pueblo que por el momento dejo de lado, debido a que su importancia para el argumento que me interesa es secundaria. Sin embargo, una comprensión completa de lo público actual como franja conceptual requiere una exploración más detallada de la radical heterogeneidad del concepto. Para un plateamiento inicial, véanse Fernández (2009) y Ortega (2013). 
excepto los funcionarios europeos y las élites americanas ${ }^{12}$. Según la visión prevalente del periodo, el pueblo era una masa irascible, ignorante, violenta e incapaz de actuar políticamente, "un monstruo indomable que a todo lo bueno se resiste”, como decía el arzobispo virrey Caballero y Góngora (1989, 411).

Con la crisis política de principios de siglo XIX y la construcción de nuevas repúblicas, este sentido de la palabra pueblo no va a desaparecer, sino que va a coexistir con un nuevo y sorprendente sentido. Se trata de una transformación lenta, que se anuncia incluso antes de la crisis política, pues recordemos que en 1803 el diccionario incorporaba un nuevo sentido de república: "estado en que gobierna el pueblo en parte o por sí, y en parte por medio de algunos ciudadanos escogidos. Respublica, democratia" (Real Academia Española 1803). En este caso, pueblo no hace referencia a la plebe sino al conjunto deliberante de los miembros de una comunidad cuyos derechos políticos les permite tomar decisiones sobre el gobierno. Este nuevo sentido aparece desde el comienzo de la crisis política de 1810, cuando las transformaciones lideradas por las élites neogranadinas encontraban en la invocación al pueblo la instancia soberana y, en su movilización, el agente de transformación del orden político. A partir de entonces y hasta el presente, el pueblo se tornó en el público de la república, el sujeto y el objeto de la política.

Los contemporáneos percibieron la novedad, aunque a menudo consideraron que podían controlar a ese nuevo pueblo. José Acevedo Gómez, también conocido como el Tribuno del Pueblo, estaba convencido el 20 de julio de 1810 de que "[...] el pueblo bajo es siempre un instrumento que nosotros manejaremos en bien y provecho de la causa de la libertad" (Acevedo de Gómez 1861, 145). Sin embargo, el pueblo resultó menos maleable de lo esperado y a aquel que inicialmente había sido alabado como "el entusiasta pueblo bravo, amante de la libertad" se le comenzó a temer como a un terrible peligro. Para el 23 de julio, un decreto de la nueva junta de gobierno anuncia:

Pueblo ilustre de Santafé es preciso que os acordéis que [...] habéis depositado vuestra confianza para salvar la patria en una junta suprema, compuesta de vuestro ilustre ayuntamiento [...] y de los ciudadanos que vos mismo habéis proclamado. Tiempo es ya [...] que ceséis en vuestra inquietud, y vuestros clamores. Dejad obrar a vuestros representantes. Si les queréis imponer la necesidad de suscribir a todas vuestras demandas [...] entended que destruís vuestra obra: no existe la autoridad

\footnotetext{
12 Es importante señalar que tal formulación permite situar al pueblo neogranadino en relación a la categoría de subalterno propuesta por Ranajit Guha en su texto programático Elementary Aspects of Peasant Insurgency in Colonial India (1983).
} 
que habéis creado [...] hacéis un monstruo de dos cabezas, queriendo a un tiempo obedecer y mandar. (Pey y Torres 1810,1)

La presencia amenazante de ese monstruo de dos cabezas, que manda y debe obedecer al mismo tiempo, hará que cesen las invocaciones a la soberanía activa del pueblo y se adopte, en cambio, el modo pasivo por medio del cual el pueblo cede su potencia soberana a la asamblea, través de la representación de los delegados.

Esa calidad monstruosa del pueblo lo convirtió en un objeto de control y represión. La misma Suprema Junta de Gobierno declaró como "reo de estado y de la patria a cualquiera que con cualquier pretexto, y no haciéndolo con la debida moderación, decoro y respeto haga la menor oposición a las órdenes de la junta” (Martínez y Quintero 2008, 26). No resulta una exageración afirmar que prácticamente todos los gobiernos posteriores exhibieron temor hacia este pueblo, lo cual explica las diversas medidas que buscaban circunscribir la vida política de la república a un grupo pequeño de patricios, tales como la ciudadanía pasiva o la democracia censitaria. Sin embargo, aunque estas medidas represivas caracterizaron buena parte de la relación del aparato público colombiano con el pueblo, el estado buscó, a partir de la segunda mitad del siglo XIX, regularizar su relación con el pueblo a través de una pedagogía moralizante.

Sin embargo, el pueblo se resiste a ser solo una modalidad pasiva, una jurisdicción sin el poder que la hace jurisdicción (Palti 2007, 119-20). Es, igualmente, el agente de la transformación y la legitimación política, es decir, el catalizador de aspiraciones colectivas y el medio a través del cual se ratifica o se revoca un mandato o un ordenamiento. Las continuas movilizaciones que afectaron el largo siglo XIX indican que gran parte de la población había incorporado expectativas acerca de su capacidad para legitimar proyectos colectivos a través de la participación política. A mediados del siglo XIX, surgieron varios movimientos artesanos urbanos que procuraron ensanchar el espacio político, asegurar el sufragio universal y defender la economía artesanal local. Según los mismos artesanos, la república había sido un logro del pueblo. Antes de 1810, señalaba un panfleto, el pueblo "componíase [...] de todos los hombres de distintos colores, cuya masa se ha llamado hasta hoy, el bajo pueblo. Esta clase no es afortunada, no es libre, ni adelanta, ni sale de aquel estado de inercia y humillación en que la dejaron los peninsulares [...]" (Escobar Rodríguez 1990, 380). El movimiento artesanal — como los posteriores movimientos sindicales en el siglo $\mathrm{XX}$ - se propuso profundizar la democratización que había empezado con la fundación de la república, pero que había quedado inconclusa debido a las medidas 
excluyentes impuestas por los regímenes oligárquicos. Al grito de "hoy el pueblo es el soberano", los artesanos marcharon contra el presidente y realizaron, en abril de 1854, el primer y único golpe de estado a manos del pueblo en Colombia ("El pueblo y el Ejército" 1854). En diciembre del mismo año, los partidos políticos tradicionales hicieron frente común y retomaron el poder para, desde entonces, asumir una posición de gran cautela al apelar al pueblo. Para finales del siglo XIX, el concepto abstracto de nación había reemplazado al pueblo como instancia soberana y la democracia había sido redefinida como "un artificio ingenioso para que gobierne la minoría y que el mayor número la apoye y sostenga con su fuerza física en el concepto de ser él quien gobierna” (Arboleda 1951, 180).

La estructura dual del concepto pueblo - agente político y objeto de control- ha puesto en el centro de la vida política del país el problema de la representación. Un buen ejemplo - pero no el único- lo ofrece el caudillo, un hombre carismático, a menudo de origen plebeyo, que jugó un papel decisivo en la vida política del siglo XIX y que insistió en representar mejor al pueblo americano que aquellas figuras patricias y civilistas. El historiador venezolano Laureano Vallenilla Lanz desmentía, en la década del veinte, la idea común de que los caudillos representaban pulsiones antidemocráticas. Para Vallenilla, el caudillo —como Bolívar, Obando o Mosquera- constituía la expresión legítima de una sociedad heterogénea y aún semicivilizada; representaba la "expresión concreta de los instintos políticos de nuestro pueblo” $(1991,136)$. Para Vallenilla, los americanos

[...] pueden considerarse como un grupo social inestable, según la clasificación científica, porque entonces y aún en la actualidad se halla colocado en el periodo de transición de la solidaridad mecánica a la solidaridad orgánica, que es el grado en que se encuentran hoy las sociedades legítimas y estables, se agrupaba instintivamente alrededor del más fuerte, del más valiente, del más sagaz, en torno a cuya personalidad la imaginación popular había creado la leyenda, que es uno de los elementos psicológicos más poderosos del prestigio; y de quien esperaban la más absoluta protección, la impunidad más completa a que estaban habituados. (1991, 136-137)

Como muchos otros intelectuales latinoamericanos de la época, para Vallenilla se gestaba en América un nuevo tipo de cultura, producto de las culturas y razas del mundo, que conllevaría la realización total de la democracia popular y que aboliría para siempre la desigualdad entre los individuos y las naciones. Para que ese gran destino glorioso se realizara, la construcción institucional y social de lo público debía plegarse a las necesidades autoritarias de la democracia 
del caudillo. Una vez más, nos encontramos con la tensión inaugural del pueblo, aquella que se da entre agente político y objeto de control.

\section{Publicidad: representar e instruir al pueblo "idiota"}

Si la república constituye el escenario y el pueblo, el sujeto de lo público, la publicidad es el trabajo al que se ve sometido ese sujeto. Por medio de ese trabajo, el pueblo adquiere su calidad de agente transformador y de legitimación, y pasa a ser, simultáneamente, objeto de pedagogía moralizante. Como las otras dos estructuras de sentido, república y pueblo, la publicidad igualmente abre dos campos de posibilidades políticamente opuestas.

El término público aparece de manera decidida a finales del siglo XVIII, asociado al sintagma opinión pública (Ortega 2012; Ortega y Chaparro 2012). Este término resulta bastante más complejo de lo que podemos suponer hoy en día. En primera instancia, aparece asociado a otro término, igualmente novedoso: la voluntad general, es decir, la disposición de una comunidad por medio de la cual se realizaba su verdadero destino. La voluntad general contrastaba con los intereses particulares y, bajo el sistema monárquico, estaba encarnada en el príncipe soberano. El influyente ilustrado español Jovellanos fue uno de los primeros en usar regularmente el sintagma opinión pública para designar una "fuerza [que] es superior a todas las sumas de fuerzas de que puede disponer la sociedad y aun todos los medios que pueda emplear” $(1956,413)$. Sus agentes eran los ilustrados, verdaderos intérpretes de la voluntad general, y sus medios eran la imprenta, los periódicos y las tertulias. A través de ellos, señalaba Jovellanos, la opinión pública “obra a un mismo tiempo en todos los puntos del territorio social, y de aquí la extensión de su influjo. Juzga todos los actos del gobierno, y de aquí la generalidad de su influjo" $(1956,413)$.

Esa opinión pública que se opone a la mera opinión —engañosa y siempre asociada al interés mezquino - es altruista, habla en nombre de todos y tiende, inevitablemente, al bien común. Su influencia benéfica — fuente de utilidad común, motor de progreso y principio de felicidad del universo-resulta un tópico verdaderamente manido en la prensa del periodo. Pero la opinión pública no es la suma de las opiniones de todos, ni tan siquiera de la mayoría:

donde falta la instrucción no hay opinión pública, porque la ignorancia no tiene opinión decidida, y los pocos que saben, bien o mal, dan la suya 
a los que no la tienen. Desde entonces, la opinión pública está por decirlo así, al arbitrio de estos pocos. (Jovellanos 1956, 413)

Estos pocos tenían como función fijar la opinión pública, es decir, instruir a los lectores para que actuaran conforme a la voluntad general. La leyenda Disfraz y pluma de todos, que encabezaba el Redactor Americano (1806), uno de los primeros impresos periódicos neogranadinos, evidencia que el periódico se definía en función de esa tarea pedagógica (Ortega y Chaparro 2012).

Aunque, ya para finales del régimen monárquico, la opinión pública emergía como una estructura social de carácter discursivo que mediaba entre las instituciones de gobierno y el conjunto de la sociedad — de modo que establecía los cimientos de la esfera pública y la sociedad civil ${ }^{13}$ - , fue con la institución del régimen republicano que ocurrió una mutación profunda en el sentido y la función de la opinión pública. De hecho, la revolución de 1810 se llevó a cabo en nombre de la opinión pública, y la imprenta y la prensa fueron celebradas como garantes de la libertad y de los fundamentos de un nuevo orden político. Ese nuevo lugar reclamaba para la prensa una distancia ante el gobierno, un espacio de crítica y de veeduría, y proponía la práctica deliberativa como ejercicio esencial de la ciudadanía a través de la cual se construía la vida en común.

Sin embargo, los forjadores de opinión en la naciente esfera pública republicana se resistían a abandonar el ideal monista, la idea de que el objeto de la opinión pública era evidenciar la voluntad general; una suerte de ley abstracta que encarnaba el bien supremo. Más aún cuando el pueblo, como ya lo vimos con el levantamiento de 1854, también tenía su publicidad, generalmente ruidosa y oral, de taller, chichería, plaza y mercado; una publicidad beligerante capaz de convertir al pueblo en actor político. La opinión pública se siguió entendiendo por mucho tiempo como patrimonio de las élites ilustradas, que veían en la prensa y la imprenta los medios para “instruir al pueblo idiota”, como señalaba el editorialista de Aviso al Público en 1810 (140). El objetivo, formulado en un lenguaje impecablemente republicano, era "conducir a la instrucción de los pueblos en sus verdaderos derechos; y en sus deberes; a formar el espíritu público de la nación; a rectificar y fixar [sic] la opinión pública [...]” (“Prospecto” 1813, 1). Pero esa intransigencia se extendía a la oposición, se consideraba que todo aquel

Esta definición se acerca vagamente a la ya clásica que Jürgen Habermas ofreció en Historia y crítica de la opinión pública: la transformación estructural de la vida pública (1986). Sin embargo, esta referencia indirecta no debe tomarse como una aceptación incondicional del paradigma habermasiano para explicar el surgimiento de la esfera pública en Iberoamérica. Para una crítica más elaborada al modelo habermasiano, véanse Guerra (2002), Guerra y Lempérière (1998) y Palti (2004). 
cuyo punto de vista difiriera en cuestiones religiosas, económicas o políticas estaba en franco desacuerdo. Es por eso que las guerras del siglo XIX consistieron principalmente en enfrentamientos de opinión y fueron producidas en nombre de la opinión pública, así como ejecutadas en los medios de opinión y dirigidas a condenar y excluir otras opiniones.

Para comienzos del siglo XX, el concepto de opinión pública cambiará, entre otras razones, porque la lógica comercial permitirá emprender un proceso de profesionalización del periodismo y adquirir mayor independencia frente al discurso pedagógico ilustrado. A partir de ese momento, el tono moralizante perderá terreno y la publicidad como empresa comercial y de entretenimiento lo ganará. La diversidad de opiniones pasará gradualmente a ser constitutiva de un mundo plural, dominado ya no por un público sino por públicos consumidores. Sin embargo, el tono civilizatorio rara vez estará lejos e incluso, en los momentos más estridentes, la figura del periodista se revestirá del ropaje sacerdotal. Según los propios publicistas, para principios del siglo XX,

[...] esa nobilísima tarea [de periodista] implica el abandono de la personalidad propia, para investirse cual nuevo Cristo, con los pecados y con las necesidades del pueblo, para pedir desde el calvario de la prensa, el perdón de los primeros y la satisfacción de las segundas. El periodista no es el hombre mezquino, lleno de odios, es el sacerdote de la idea, el abogado de la civilización, el escudo del pueblo contra las arbitrariedades de arriba, el sostén legítimo contra la pica devastadora de los revoltosos, el guardián del tesoro público, el eco moderador de las medidas arbitrarias, el arma en fin poderosísima que tiene una sociedad para defenderse de todo lo que trate de disolverla o de atacar sus cimientos. Eso es ser periodista. Los demás son pasquineros. (“Amargas verdades” 1910) ${ }^{14}$

Este publicista aurático no encarna el ideal deliberante, plural y diverso de un cuerpo social heterogéneo, sino la verdad ilustrada, en este caso revelada.

\section{Población: calcular con mayor precisión}

Finalmente, estos tres nodos conceptuales están atravesados y son dinamizados por una concepción de la población que se hace posible a finales del siglo XVIII, 
cuando un grupo pequeño pero influyente de pensadores ilustrados descubren en los habitantes la fuente de riqueza del reino y buscan transformar a la plebe en un objeto de investigación legítimo. Un nuevo término, la población, permite objetivar esa masa informe y convertirla en la materia prima de potenciales productores, trabajadores y consumidores, piezas y engranajes de un todo que debe ser laborioso y armonioso. Esa potencia viva que se descubre en los cuerpos previamente abyectos de la plebe permite concebir una perfectibilidad del orden social ausente hasta ese momento. Desde entonces, la población alimenta el discurso sobre la producción de la riqueza de las naciones - es decir, la economía política- y se conecta firmemente con la realización del bienestar y la felicidad humana.

Por encima de todo, la población se convirtió en el objeto de administración y regulación, y no es fortuito que aparezca el término popular para designar las políticas destinadas a abarcar las clases plebeyas. Con ese sentido es que el ilustrado español Pedro Rodríguez de Campomanes usa el término, para agitar el debate de la necesidad de extender la educación práctica a las clases artesanas a finales del siglo XVIII. Para entonces, la plebe ya no está del todo marginada, su suerte ahora es la suerte del naciente estado $(1775,2)$.

Las ciencias se afianzan como instrumento para investigar al pueblo. Francisco José de Caldas, naturalista, geógrafo y director del Semanario de la Nueva Granada, rogó a sus contemporáneos ilustrados:

[...] calculemos con la mayor frecuencia y con toda la exactitud posible el número de habitantes de cada provincia y de cada pueblo; estudiemos la constitución física, el carácter, las virtudes, los vicios, las ocupaciones del hombre que habita bajo de climas tan diferentes y aun opuestos; la educacion física y moral que se da actualmente, y la que más convenga a cada punto; las enfermedades más frecuentes, las epidemias, las tablas necrológicas y cuanto puede mejorar y hacer feliz al hombre. $(1849,167)$

Para asegurar la productividad del pueblo, que constituye la felicidad del estado, Caldas se propone regular el trabajo, reglar los espacios en los que el pueblo labora, indagar sobre sus valores, prácticas y relaciones, proteger su salud y establecer una higiene pública, y así sucesivamente y de manera cada vez más invasiva. Las transformaciones semánticas resultan, en buena medida, del crecimiento de grupos sociales que, por una parte, son potenciales manos de obra y, por otra, constituyen la riqueza del reino. La aparición del urbanismo, el discurso higienista y la educación técnica son manifestaciones parciales de esa lógica disciplinar. El estado busca convertir en pueblo a la plebe, tránsito que se hace a partir de una lógica disciplinaria y nunca democrática. 


\section{Conclusión}

Esta ha sido una visión inicial muy general y bastante fragmentaria del modo en que lo público surgió como estructura de experiencia social durante los primeros cien años de experiencia republicana. Mi objetivo ha sido demostrar que lo público no existe como modelo definido, que no es, como pretenden la filosofía, la ciencia política o la sociología política, un cuadro normativo. La historia que nos ofrecen las dos argumentaciones encontradas que examinamos al principio de este artículo resulta insuficiente para comprender el problema. Así pues, no es una cuestión de un modelo que puede ser verdadero o falso, sino que más bien se trata de una franja de experiencia y un horizonte de expectativa dentro de los cuales algunas cosas se hacen posibles y otras, imposibles.

En segundo lugar, la convergencia de los cuatro nodos de sentido en lo público evidencia que ambas posiciones, la maximalista y la minimalista, están implicadas mutuamente y que lo público solo se puede entender desde esa convergencia. Suponer que nuestro reto se reduce a tomar partido por una de las dos trincheras existentes significa aceptar los términos del debate, tal y como aparecen definidos en la actualidad, y renunciar por lo tanto a enfrentar con imaginación crítica los retos del presente. Esto, claro está, no se puede hacer sin abandonar las (mis) convicciones personales, que ven en lo público un principio vigoroso de democratización y redistribución necesaria en nuestro país.

En tercer lugar, como resulta evidente a lo largo de este escrito, cada uno de los nodos de sentido implicados en lo público - la república, el pueblo, la opinión pública y la población- presenta una tensión que ha resultado productiva y violenta a la vez, a lo largo de la historia. Es por eso que lo público aparece atravesado por la misma estructura de opuestos que caracteriza a cada uno de sus tributarios conceptuales, simultáneamente dinamizado por una pulsión emancipatoria y por otra que llama a la represión y el control, que le da vida a la existencia política del pueblo mientras se dota de instrumentos a los grupos de poder para instruirlo y someterlo. No es posible pensar lo público, al menos no por el momento, al margen de esa tensión; ella es nuestra aporía o nudo histórico de larga duración.

Por último, quiero sugerir un cuarto punto, que no se infiere directamente de lo que he presentado, y que, por lo tanto, aventuro a modo de hipótesis. De los cuatro nodos conceptuales, dos - la república y el pueblo- están en profunda crisis. Se trata de la crisis política de lo público, del agotamiento de horizontes de expectativa. La crisis actual de estas ficciones pone en riesgo el futuro de lo público como franja de experiencia contemporánea y como 
elemento estructurante de lo político. Hasta hoy en día lo público había sido indispensable para la construcción de nuestra experiencia colectiva. ¿Será que ha dejado de ser útil o necesario? ¿Estaríamos dispuestos a asumir un nuevo mundo feliz, despojado de lo público? ¿O tendremos el valor y la imaginación que requieren los tiempos presentes para repensar lo público-democrático como pieza central en la construcción de la sociedad futura?

\section{Referencias}

Acevedo de Gómez, María Josefa. 1861. Cuadros de la vida privada de algunos granadinos, copiados al natural para instrucción y divertimiento de los curiosos. Bogotá: Imprenta del Mosaico.

“Amargas verdades”. 1910. La Fusión: Periódico Político, Literario y de Variedades, 26 de enero. Biblioteca Nacional de Colombia.

Arboleda, Sergio. 1951. La república en la América Española (1869). Biblioteca Popular Colombiana. Bogotá: ABC.

“Avisos de Hebephilo”. 1791. Papel Periódico, $1 .^{\circ}$ de abril. Biblioteca Nacional de Colombia.

Bolívar, Simón. 2009. Doctrina del Libertador. 3. ${ }^{a}$ ed. corregida y aumentada, editado por Manuel Pérez Vila. Caracas: Biblioteca Ayacucho.

Caballero y Góngora, Antonio. 1989. "Relación del estado del Nuevo Reino de Granada, que hace el arzobispo obispo de Córdoba a su sucesor el Excmo. Sr. D. Francisco Gil y Lernos. Año de 1789”. En Relaciones e informes de los gobernantes de la Nueva Granada, vol. 3, editado por Germán Colmenares, 361-499. Bogotá: Fondo de Promoción de la Cultural del Banco Popular.
Caldas, Francisco José de. 1849. Semanario de la Nueva Granada: miscelánea de ciencias, literatura, artes e industria. Nueva edición, corregida y aumentada con varios opúsculos inéditos. París: Librería Castellana.

“Continuación al n. ${ }^{\circ}$ 15”. 1811. Aviso al Público, 15 de enero, 140.

Escobar Rodríguez, Carmen. 1990. La revolución liberal y la protesta del artesanado. Bogotá: Suramérica.

Fernández Sebastián, Javier. 2009. Diccionario político y social del mundo iberoamericano. Madrid: Centro de Estudios Políticos y Constitucionales; Fundación Carolina.

Finestrad, Joaquín de. (1789) 2000. Vasallo instruido en el estado del Nuevo Reino de Granada y en sus repectivas obligaciones, editado por Margarita González. Bogotá: Universidad Nacional de Colombia.

Friedman, Milton. 1962. Capitalism and Freedom. Chicago: University of Chicago Press.

Guerra, François Xavier. 2002. “'Voces del pueblo’. Redes de comunicación y orígenes de la opinión en el mundo hispánico (1808-1814)”. Revista de Indias 62 (225): 357-384.

Guerra, François Xavier y Annick Lempérière. 1998. Los espacios públicos en 
Iberoamérica. Ambigüedades y problemas. Siglos XVIII-XIX. México D. F.: Fondo de Cultura Económica.

Guha, Ranajit. 1983. Elementary Aspects of Peasant Insurgency in Colonial India. Delhi: Oxford University Press.

Habermas, Jürgen. 1986. Historia y crítica de la opinión pública. La transformación estructural de la vida pública. Barcelona: Gustavo Gili.

Hayek, Friedrich. 1944. The Road to Serfdom. Chicago: University of Chicago Press.

Harvey, David. 2005. A Brief History of Neoliberalism. Oxford: Oxford University Press.

Jovellanos, Gaspar Melchor de. (ca. 1789) 1956. "Reflexiones sobre la opinión pública”. En Obras publicadas e inéditas, editado por Cándido Nocedal, 5 vols., $B A E$ 87. Madrid: Atlas.

Koselleck, Reinhart. 1993. Futuro pasado. Para una semántica de los tiempos históricos. Barcelona: Paidós.

Laso de la Vega, Benito. 1826. Exposición que hace el diputado al Congreso por la provincia de Puno. Lima: Imprenta Republicana Administrada.

Lefort, Claude. 1991. Ensayos sobre lo político. Guadalajara: Universidad de Guadalajara.

Martínez Garnica, Armando e Inés Quintero Montiel. 2008. Actas de formación de juntas y declaraciones de independencia (1809-1822). Reales Audiencias de Quito, Caracas y Santafé. Bucaramanga: Universidad Industrial de Santander.

Montesquieu, Charles de Secondant. (1735) 2007. Del espíritu de las leyes. Traducción de Mercedes Blázquez y Pedro de la Vega. Madrid: Tecnos.

Ortega Martínez, Francisco A. 2012. "La publicidad ilustrada y el concepto de opinión pública en la Nueva Granada”. Fronteras de la Historia 17 (1): 15-47.

-. 2013. "And where Are the People?: Genealogies of the Pueblo during the Late Eighteenth and Early Nineteenth Century”. En Latin American Popular Culture: Politics, Media, Affect, editado por Geoffrey Kantaris y Rory O’Brien, 45-70. Rochester: Tamesis Books.

Ortega Martínez, Francisco A. y Alexander Chaparro. 2012. Disfraz y pluma de todos: opinión pública y cultura política, siglos XVIII y XIX. Bogotá: Universidad Nacional de Colombia.

Palti, Elías. 2004. “Guerra y Habermas: ilusiones y realidad de la esfera pública latinoamericana”. En Conceptualizar lo que se ve. François-Xavier Guerra historiador, homenaje, editado por Erika Pani y Alicia Salmerón, 419-460. México D. F.: Instituto Mora.

-. 2007. El tiempo de la política. El siglo XIX reconsiderado. Buenos Aires: Siglo XXI.

Pey, José Miguel y Camilo Torres. 1810. "Proclama" de la Junta de Gobierno del 25 de julio. Sala de Libros Raros y Manuscritos, Biblioteca Luis Ángel Arango, Bogotá

Pocock, John Greville Agard. 2002. El momento maquiavélico. El pensamiento político florentino y la tradición republicana atlántica. Traducción de Marta Vázquez-Pimentel y Eloy García. Madrid: Tecnos.

“Prospecto”. 1813. Argos de la Nueva Granada, 11 de noviembre. Biblioteca Nacional de Colombia.

“El pueblo y el Ejército". 1854. 17 de abril de 1984, 23 de julio. Biblioteca Nacional.

Real Academia de la Lengua Española. 1780. Diccionario de la lengua castellana: reducido a un tomo para su más fácil uso. Madrid: Joaquín Ibarra. 
-.1803. Diccionario de la lengua castellana: reducido a un tomo para su más fácil uso. Madrid: Joaquín Ibarra.

Rocafuerte, Vicente. 1823. Ensayo político. El sistema colombiano, popular, electivo, y representativo es el que más conviene a la América independiente. Nueva York: Imprenta de A. Paul.

Rodríguez Campomanes, Pedro. 1775. Discurso sobre la educación popular de los artesanos y su fomento. Madrid: Imprenta de don Antonio de Sacha.

Rojas, Rafael. 2009. Las repúblicas de aire. Utopía y desencanto en la revolución de Hispanoamérica. México: Taurus.

Rosanvallon, Pierre. 2003. Por una historia conceptual de lo político. México D. F.: Fondo de Cultura Económica.
Stanislaw, Joseph y Daniel Yergin. 1998. The Commanding Heights: The Battle between Government and the Marketplace that Is Remaking the Modern World. Nueva York: Free Press.

Stiglitz, Joseph. 2002. Globalization and its Discontents. Nueva York: Norton.

Vallenilla Lanz, Laureano. 1991. Cesarismo democrático y otros textos. Caracas: Biblioteca Ayacucho.

Williamson, John. 1990. "What Washington Means by Policy Reform”. En Latin American Readjustment: How much Has Happened, editado por John Williamson, 7-38. Washington: Institute for International Economics. 